\title{
Derivatives of Spiropentadiene Dication: New Species with Planar Tetracoordinate Carbon (ptC) atom
}

\author{
Caio L. Firme,* Octávio A. C. Antunes, Pierre M. Esteves,* and Rodrigo J. Corrêa \\ Universidade Federal do Rio de Janeiro, Instituto de Química, Avenida Athos da Silveira Ramos, \\ 149, CT Bloco A, Sala 622, Cidade Universitária - Ilha do Fundão Rio de Janeiro, BR 21941-909, Brazil
}

Received: August 18, 2008; Revised Manuscript Received: January 21, 2009

\begin{abstract}
In this work, nine tetrasubstituted derivatives $\left[\mathrm{NH}_{2}, \mathrm{OCH}_{3}, \mathrm{Li}, \mathrm{Na}, \mathrm{Si}\left(\mathrm{CH}_{3}\right)_{3} / \mathrm{SiH}_{2} \mathrm{CH}_{3}, \mathrm{P}\left(\mathrm{CH}_{3}\right)_{2}, \mathrm{Cl}, \mathrm{F}\right.$, and $\mathrm{CN}$ ] of the spiropentadiene dication were analyzed within the framework of QTAIM. In the studied series, the electron-withdrawing substituents destabilize the ptC-containing spiropentadiene dication. On the other hand, stabilization of this dication is possible for electron-donating substituents only through $\sigma$ bonds, such as Li and $\mathrm{Na}$. In all studied systems, according to QTAIM, the $\pi$-electron system does not participate in the stabilization of the $\mathrm{ptC}$ atom in the spiropentadiene dication. $\sigma$-electron-donating groups stabilize the spiropentadiene dication system by increasing the charge density of $\mathrm{C}_{\mathrm{ext}}-\mathrm{ptC}$ bonds, whereas electronwithdrawing groups remove the charge density from $\mathrm{C}_{\mathrm{ext}}-\mathrm{ptC}$ bonds.
\end{abstract}

\section{Introduction}

Molecules containing planar tetracoordinate carbon atoms (ptCs) have represented a great turning point in the paradigms of chemistry. ${ }^{1-11}$ Both mechanical ${ }^{12-14}$ and electronic ${ }^{9,15,16}$ strategies for obtaining species with $\mathrm{ptC}$ atoms have been used. In the former, the planarization of the carbon atom occurs via highly constrained moieties bonded to it. In the latter, the $\sigma$-donating and $\pi$-accepting groups surrounding the carbon atom enable its planarization. In theoretical approaches, to date, the B3LYP hybrid density functional is still the preferred method for studying species with $\mathrm{ptC}$ atoms when no weak interactions are involved. ${ }^{17-21}$

Small molecules containing ptC atoms have been successfully designed. ${ }^{22}$ Our group and others have reported different molecules containing ptC atoms, ${ }^{18}$ opening a new dimension in chemistry. Analogues of spiropentadiene exhibit ptC atoms in the dication structure, ${ }^{23-25}$ but dianion species with similar molecular skeletons also have a central planar tetracoordinate carbon atom. ${ }^{26-28}$ The dianion $\mathrm{C}_{5}{ }^{2-}$ can actually be thought as a spiropentadiene without four protons and with a dication core. ${ }^{29}$ Our group also has proposed two new neutral hydrocarbons containing no heteroatoms with a central ptC, using the spiropentadiene dication moiety as an inspiration. ${ }^{30}$

The quantum theory of atoms in molecules ${ }^{31-33}$ (QTAIM) can reveal much important information about the electronic nature of a molecular system. In our previous work, ${ }^{18}$ QTAIM analysis indicated that the $\pi$ electrons do not contribute to the planarization of the central carbon in spiropentadiene dication, suggesting a more profound study about the consequences derived from those observations. Thus, in this work, we extend that study to derivatives of spiropentadiene with electrondonating and electron-withdrawing substituents in order to provide further insight into the chemistry of this new class of organic compounds.

* To whom correspondence should be addressed. E-mail: pesteves@ iq.ufrj.br (P.M.E.) or cfirme@iq.ufrj.br (C.L.F.).

\section{Computational Details}

The geometries of the species were optimized using standard techniques. ${ }^{34}$ Vibrational analysis of the optimized geometries at selected points on the potential energy surface was carried out to determine whether the resulting geometries were true minima or transition states, by checking for the existence of imaginary frequencies. Calculations were performed at the B3LYP/6-311++G** and PBE1PBE/6-311++G** levels ${ }^{35-39}$ using the Gaussian 03 package. ${ }^{40}$ Electronic densities were derived from the Kohn-Sham orbitals obtained at the B3LYP/ $6-311++\mathrm{G}^{* *}$ level for further QTAIM calculations. All topological data were calculated by means of AIM2000 software. ${ }^{41}$ All energy differences were calculated at $298.15 \mathrm{~K}$ and $1 \mathrm{~atm}$.

\section{Results and Discussion}

Figure 1 shows the derivatives of the spiropentadiene dication (1-6) with ptC atoms and their corresponding $\mathrm{C}_{\mathrm{ext}}-\mathrm{C}_{\mathrm{ext}}$ and $\mathrm{C}_{\text {central }}-\mathrm{C}_{\mathrm{ext}}$ bond lengths in the spiropentadiene moiety. Other tetrasubstituted spiropentadiene dications were evaluated, but the species $\mathrm{X}_{4} \mathrm{C}_{5}{ }^{2+}$ where $\mathrm{X}=\mathrm{NH}_{2}, \mathrm{P}\left(\mathrm{CH}_{3}\right)_{2}$, and $\mathrm{OCH}_{3}$ do not have $\mathrm{ptC}$ atoms.

From Figure 1, one can see two different groups of spiropentadiene systems. The first encompasses $\mathrm{Li}$ - and Na-tetrasubstituted species and $\mathrm{Si}\left(\mathrm{CH}_{3}\right)_{3} / \mathrm{SiH}_{2} \mathrm{CH}_{3}$-disubstituted species, and the second includes $\mathrm{CN}-, \mathrm{Cl}-$, and F-tetrasubstituted species. In comparison with the hydrogen-tetrasubstituted spiropentadiene dication species, one can observe the following tendencies: (1) the electron-withdrawing groups $\mathrm{F}, \mathrm{CN}$, and $\mathrm{Cl}$ cause a small increase in the $\mathrm{C}_{\mathrm{ext}}-\mathrm{C}_{\mathrm{ext}}$ bond, along with a decrease in the $\mathrm{C}_{\text {central }}-\mathrm{C}_{\mathrm{ext}}$ bond length; (2) the electron-donating groups cause nearly $13 \%$ and nearly $1 \%$ increases in the $\mathrm{C}_{\text {ext }}-\mathrm{C}_{\mathrm{ext}}$ and $\mathrm{C}_{\text {central }}-\mathrm{C}_{\mathrm{ext}}$ bond lengths, respectively.

Table 1 lists the activation energies of ring opening for the derivatives of the spiropentadiene dication obtained at the B3LYP/6-311++G** and PBE1PBE/6-311++G** levels. The activation energies of ring opening for species $\mathbf{1}$ and $\mathbf{2}$ are higher than that for spiropentadiene dication. The corresponding activation energies for species $\mathbf{3}$ and $\mathbf{4}$ are smaller than that for spiropentadiene dication. Thus, derivatives $\mathbf{1}$ and $\mathbf{2}$ are more 


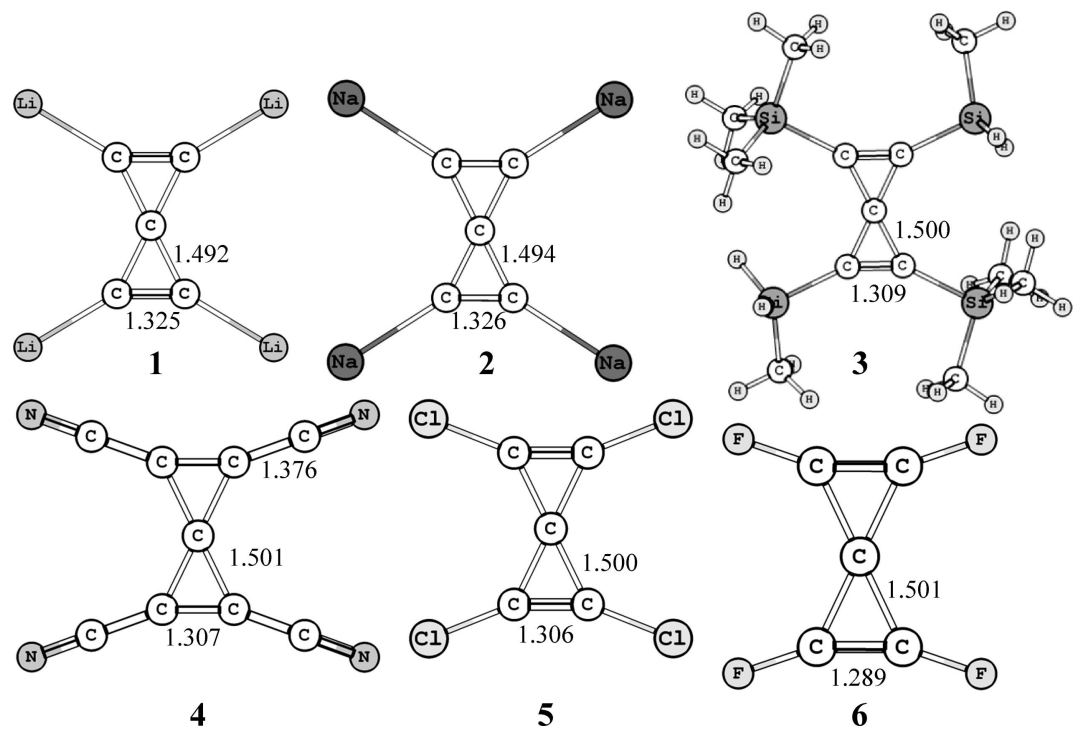

Figure 1. Derivatives of the spiropentadiene dication and their corresponding $C_{e x t}-C_{e x t}$ and $C_{\text {central }}-C_{e x t}$ bond lengths (in $\AA$ ) at the B3LYP/6$311++\mathrm{G}^{* *}$ level. For the hydrogen-substituted spiropentadiene dication, these bond lengths are 1.484 and $1.288 \AA$, respectively. ${ }^{18}$

TABLE 1: Imaginary Frequencies and Activation Energies of Ring Opening for the Derivatives of the Spiropentadiene Dication 1-4 Obtained with the B3LYP and PBE1PBE Density Functionals ${ }^{a}$

\begin{tabular}{cccc}
\hline & \multirow{2}{*}{$\begin{array}{c}\text { imaginary } \\
\text { species }\end{array}$} & \multicolumn{2}{c}{ activation energy $\left(\mathrm{kcal} \mathrm{mol}^{-1}\right)$} \\
\cline { 3 - 4 } frequencies $\left(\mathrm{cm}^{-1}\right)$ & B3LYP & PBE1PBE \\
\hline $\mathbf{1}$ & none & 4.5 & 7.1 \\
$\mathbf{2}$ & none & 4.1 & 6.3 \\
$\mathbf{3}$ & none & 0.6 & 0.6 \\
$\mathbf{4}$ & none & 1.0 & 2.5 \\
$\mathbf{5}$ & $-37.20^{b}$ & - & - \\
$\mathbf{6}$ & $-51.50^{b}$ & - & -
\end{tabular}

${ }^{a}$ Activation energy of ring opening for spiropentadiene dication is 2.3 and $4.9 \mathrm{kcal} \mathrm{mol}^{-1}$ for the B3LYP ${ }^{18}$ and PBE1PBE density functionals, respectively. ${ }^{b}$ From B3LYP calculations.

stable than the spiropentadiene dication toward the ring-opening process. However, not all types of electron-donating substituents can be used to stabilize spiropentadiene dication with ptC atom. As shown before, well-known electron-donating groups such as $\mathrm{NH}_{2}, \mathrm{P}\left(\mathrm{CH}_{3}\right)_{2}$, and $\mathrm{OCH}_{3}$ failed to form derivatives of spiropentadiene dication with ptC atoms that were minima on the potential energy surface (PES). This is probably because they are good resonance-donating groups that demand the participation of the $\pi$-electron system and the $\mathrm{ptC}$ atom of the spiropentadiene dication system is stabilized only through $\sigma$ electrons. $^{18}$

Species $\mathbf{5}$ and $\mathbf{6}$ are transition structures, as after analysis of the vibrational modes, an imaginary frequency was found corresponding to a twist at the ptC (Table 1).

Each of the derivatives of the spiropentadiene dication with electron-donating substituents, $\mathbf{1}-\mathbf{3}$, has a ptC atom and is a minimum on the potential energy surface (PES). The derivatives of the spiropentadiene dication with electron-withdrawing substituents, $\mathbf{5}$ and $\mathbf{6}$, have ptC atoms in transition structures. Noticeably, the cyano-tetrasubstituted derivative (species 4) has a $\mathrm{ptC}$ atom and is a minimum on the PES.

It is noteworthy that species $\mathbf{4}$, with the electron-withdrawing $\mathrm{CN}$ tetrasubstituent, is a relatively stable species with a ptC atom. This is a consequence of the resonance effect between the $\mathrm{sp}^{2} \mathrm{C}_{\text {ext }}$ atom and the $\mathrm{sp} \mathrm{C}(\mathrm{N})$ atom in which part of the charge density of the triple $\mathrm{CN}$ bond is transferred to the
$\mathrm{C}_{\mathrm{ext}}-\mathrm{C}(\mathrm{N})$ bond. The charge density of the bond critical point of the $\mathrm{C}_{\mathrm{ext}}-\mathrm{C}(\mathrm{N})$ bond $\left(\rho_{\mathrm{b}}=0.304 \mathrm{au}\right)$ is intermediate between those of the CC bonds of ethane $\left(\rho_{\mathrm{b}}=0.231 \mathrm{au}\right)$ and ethylene $\left(\rho_{\mathrm{b}}=0.344 \mathrm{au}\right)$. The QTAIM bond order of $\mathrm{C}_{\mathrm{ext}}-\mathrm{C}(\mathrm{N})$ bond is 1.54, and the delocalization index (DI) (1.14) is higher than that of the CC bond in ethane (DI = 0.99). The delocalization index (DI) is the amount of electrons shared between each pair of atoms. ${ }^{31,42,43}$ Furthermore, the DI of the $\mathrm{CN}$ bond $(\mathrm{DI}=2.38$ ) is smaller than the DI of the $\mathrm{CN}$ bond of acetonitrile (DI = 2.99). ${ }^{44}$ All of these data indicate that the $\mathrm{CN}$ group exhibits ambiguous behavior in the spiropentadiene dication because it donates electrons by resonance and withdraws electrons by an inductive effect. The $\mathrm{CN}$ tetrasubstituent is the only one of the studied groups that stabilizes the spiropentadiene moiety by a resonance effect, even though $\mathrm{CN}$ is a strong electron-withdrawing group. However, this stabilization is smaller than that from the nonsubstituted spiropentadiene dication.

Table 2 lists some topological information about the atomic basins $(\Omega)$ of the carbon atoms of species $\mathbf{1 - 6}$ and cyclopropenyl cation, obtained from the one-electron and two-electron integrations of the corresponding atomic basins.

The ptC atoms of species $\mathbf{1}$ and $\mathbf{2}$ are the most negatively charged of all studied species, except for $\mathbf{6}$, which is not a minimum on the PES. Species $\mathbf{3}$ and $\mathbf{4}$ have the least negative charge on the ptC atom, because of the ability of their substituents to withdraw electron density. The external carbon atoms are negatively charged in species $\mathbf{1 - 3}$ (Table 2) but positively charged in species $\mathbf{4}$. In species $\mathbf{4}$, the negatively charged core (ptC atom) is surrounded by positively charged $\mathrm{C}$ atoms. Interestingly, from the analysis of the atomic charge of the $\mathrm{C}_{\text {central }}$ atom in species 3 , the $\mathrm{Si}\left(\mathrm{CH}_{3}\right)_{3} / \mathrm{SiH}_{2} \mathrm{CH}_{3}$ substituents behave as electron-withdrawing groups instead electron-donating groups as expected. For transition structures $\mathbf{5}$ and $\mathbf{6}$, the $\mathrm{C}_{\mathrm{ext}}$ atoms have the highest positive charges.

The localization index (LI) of an atomic basin is the amount of unshared electrons within a specific atomic basin. ${ }^{42,43}$ Analysis of the LIs of $\mathrm{C}_{\mathrm{ext}}$ and $\mathrm{ptC}$ atoms provides complementary information about these species. The external carbon atoms of species $\mathbf{1 - 3}$ have the highest values of the localization index. The LI of the $\mathrm{C}_{\text {central }}$ atom parallels the values of their corresponding atomic charges for $\mathbf{1 - 3}$, that is, the more effective the electron-donating substituent, the 
TABLE 2: Atomic Charges $[q(\Omega)]$, Atomic Volumes $[v(\Omega)]$, Atomic Dipole Moments $\left[M_{1}(\Omega)\right]$, Localization Indexes $(L I s)$, and Electronic Energy Densities $\left[E_{\mathrm{e}}(\Omega)\right]$ of the External Carbon Atom and ptC Atom and Sum of the Electronic Energies of the Five Carbon Atoms of the Spiropentadiene Dication Skeleton $\left[E_{\mathrm{e}}\left(\mathrm{C}_{5}\right)\right]$ for Species 1-6 and Cyclopropenyl Cation ${ }^{a}$

\begin{tabular}{|c|c|c|c|c|c|c|c|}
\hline species & atom & $q(\Omega)$ & $v(\Omega)$ & $M_{1}(\Omega)$ & LI & $E_{\mathrm{e}}(\Omega)$ (hartree) & $E_{\mathrm{e}}\left(\mathrm{C}_{5}\right)$ (hartree) \\
\hline \multirow[t]{2}{*}{1} & external carbons & -0.397 & 146.4 & 1.32 & 4.80 & -38.1400 & -190.7098 \\
\hline & ptC atom & -0.185 & 76.6 & 0 & 4.03 & -38.1499 & \\
\hline 2 & external carbons & -0.378 & 146.9 & 1.21 & 4.75 & -38.0525 & -190.2880 \\
\hline \multirow[t]{3}{*}{3} & external carbons ${ }^{b}$ & -0.350 & 102.8 & 1.21 & 4.50 & -38.1471 & -190.5246 \\
\hline & external carbons ${ }^{c}$ & -0.263 & 100.2 & 1.21 & 4.44 & -38.0924 & \\
\hline & ptC atom & -0.136 & 75.6 & 0 & 4.00 & -38.0456 & \\
\hline \multirow[t]{2}{*}{5} & external carbons & +0.259 & 73.3 & 0.15 & 3.66 & -37.8838 & -189.0862 \\
\hline & ptC atom & -0.157 & 76.0 & 0 & 4.02 & -38.0862 & \\
\hline \multirow[t]{2}{*}{6} & external carbons & +1.038 & 56.3 & 0.62 & 3.13 & -37.4160 & -187.8032 \\
\hline & $\mathrm{ptC}$ atom & -0.220 & 79.2 & 0 & 4.12 & -38.1392 & \\
\hline cyclopropenyl cation & carbon & +0.075 & 91.5 & 0.33 & 4.01 & -38.0845 & - \\
\hline spiropentadiene dication $^{d}$ & external carbons & +0.190 & 88.2 & 0.46 & 3.94 & -37.9995 & - \\
\hline
\end{tabular}

${ }^{a} \Omega$ is the atomic basin. The atomic charge, $q(\Omega)$; the atomic volume, $v(\Omega)$; and the electronic energy density, $E_{\mathrm{e}}(\Omega)$ are in au. ${ }^{b}$ External carbon bonded to the $\mathrm{Si}\left(\mathrm{CH}_{3}\right)_{3}$ group. ${ }^{c}$ External carbon bonded to the $\mathrm{SiH}_{2} \mathrm{CH}_{3}$ group. ${ }^{d}$ Reference 18.

higher the $\mathrm{LI}$ on the $\mathrm{C}_{\text {central }}$ atom for species $\mathbf{1 - 3}$. In the case of transition structures $\mathbf{5}$ and $\mathbf{6}$, the values of LI of the $\mathrm{C}_{\text {ext }}$ atoms are the smallest within the studied series, whereas the LI values of the $\mathrm{C}_{\text {central }}$ atoms in $\mathbf{5}$ and $\mathbf{6}$ are similar to those in other species. The LI values of the $\mathrm{C}_{\text {central }}$ atoms in species $\mathbf{1 - 5}$ are very similar (Table 2 ). The LIs and atomic charges indicate that a negative charge on the $\mathrm{ptC}$ atom is a characteristic of all derivatives of the spiropentadiene dication, regardless of whether they are minima on the PES. In addition, by comparing the LI values of tetrasubstituted spiropentadienes with those of the spiropentadiene dication $\left(\mathrm{C}_{5} \mathrm{H}_{4}{ }^{2+}\right)$, only species 4-6 have smaller LI values for the $\mathrm{C}_{\text {ext }}$ than $\mathrm{C}_{5} \mathrm{H}_{4}{ }^{2+}$.

The atomic dipole moments, $M_{1}(\Omega)$, which is sensitive to the electron density far from the nucleus (the vector from the centroid of the electron density of an atomic basin pointed toward its nucleus), ${ }^{31}$ indicate spherical charge densities around the six $\mathrm{C}_{\text {central }}$ computed structures. The $M_{1}(\Omega)$ values of the $\mathrm{C}_{\mathrm{ext}}$ atoms for species $\mathbf{1 - 3}$ are the highest, indicating strongly distorted charge densities around the $\mathrm{C}_{\text {ext }}$ atoms.

All of these topological data (atomic charge, localization index, and atomic dipole moment) indicate a higher charge flux from the substituents to the $\mathrm{C}_{\mathrm{ext}}$ atoms in species $\mathbf{1 - 3}$ than in species 4-6. This charge flux is directly related to the stability of the ptC atom.

The increasing order of the electronic energy density of $\mathrm{ptC}$ atom is $\mathbf{1}<\mathbf{6}<\mathbf{4}<\mathbf{2}<\mathbf{3}<\mathbf{5}$, and the increasing order of the electronic energy density of the $C_{5}$ skeleton is $\mathbf{1}<\mathbf{3}<\mathbf{2}<\mathbf{4}<$ $\mathbf{5}<\mathbf{6}$. Obviously, there is no relationship between the electronic energy density of the $\mathrm{ptC}$ atom and the electronic energy density of the overall skeleton. Likewise, there is no linear correspondence between the increasing order of the electronic energy density of the $\mathrm{C}_{5}$ skeleton and the activation energy of the ring-opening reaction of species $\mathbf{1 - 6}$, although the lithium-, chlorine-, and fluorine-tetrasubstituted derivatives have an expected correspondence between these two relations. Certainly, not only the smaller electronic energy density of the ptC atom can be related to the higher stability of the spiropentadiene dication derivative toward ring-opening reaction. Otherwise, the fluorine-tetrasubstituted derivative would be the second most stable species. Thus, the stability of the spiropentadiene dication derivative toward the ring-opening reaction is related not only to the electronic energy density of the $\mathrm{C}_{5}$ skeleton, but also to the distribution of electron density in the valence region of the $\mathrm{C}_{5}$ skeleton (see the discussion of the data in Table 3).

The analysis of the data from Tables 1 and 2 suggests an ambiguous behavior of the electron-withdrawing groups. For example, species $\mathbf{4}$ with the $\mathrm{CN}$ tetrasubstituent has a smaller reactivity toward the ring-opening reaction than species $\mathbf{3}$ with disubstituted $\mathrm{Si}\left(\mathrm{CH}_{3}\right)_{3} / \mathrm{SiH}_{2} \mathrm{CH}_{3}$ groups. Species 6 , tetrasubstituted with $\mathrm{F}$, is a transition structure, but its $\mathrm{ptC}$ atom has the second smallest electronic energy density.

The atomic charge and atomic volume of the carbon atoms of the cyclopropenyl cation are very different from those of species 1-6 (in Table 2). Even the values of the atomic dipole moment of the carbon atoms of the cyclopropenyl cation are very different from those of species $\mathbf{1}$ and 2. This QTAIM analysis indirectly indicates that the planarization of the central carbon in spiropentadiene dication does not have contribution from $\pi$ electrons as these parameters in species $\mathbf{1 - 6}$ are different from those in the cyclopropenyl cation.

None of the atomic properties of the ptC atoms from Table 2 differentiate species $\mathbf{1 - 4}$ (which are minima on the PES) from species $\mathbf{5}$ and $\mathbf{6}$ (which are transition structures).

Table 3 shows the topological information between each bonding atomic pair in the $\mathrm{C}_{5}$ skeleton and its neighbor groups for species 1-6. Except for the delocalization index (DI), all other information was obtained at the bond critical point (BCP) between the pair of atoms. The bond critical points of species 6 are shown in Figure 2. The bond critical point is a saddle point between each bonding pair of atoms that also belongs to the zero-flux surface. In all points of the zero-flux surface, the scalar product of the normal vector $(\vec{n})$ and gradient of the charge density $(\nabla \rho)$ is zero $(\nabla \rho \cdot \vec{n}=0){ }^{31,33}$

In Figure 2, there are two topological structures of species 6. Figure $2 \mathrm{~A}$ represents the molecular graph of $\mathbf{6}$, and Figure $2 \mathrm{~B}$ represents its virial path. The lines of atomic interactions in the molecular graph of Figure 2A are called bond paths and represent the highest charge density distribution between each pair of atoms. The critical points of the charge density are obtained where $\nabla \rho=0$. The bond paths are always mirrored by their virial paths in Figure $2 \mathrm{~B}$. The virial paths represent the region where the potential energy density is maximally negative between each bonding atomic pair. ${ }^{45}$ One can see that 
TABLE 3: Charge Densities $(\rho)$, Laplacians of the Charge Density $\left(\nabla^{2} \rho\right)$, Ellipticities $(\epsilon), \mid \lambda_{1} 1 / \lambda_{3}$ Ratios, and Total Energy Densities $\left(H_{b}\right)$ of the Bond Critical Points (BCPs) of Species 1-6 and Delocalization Indexes (DIs) and QTAIM Bond Orders of Their Corresponding Atomic Pairs

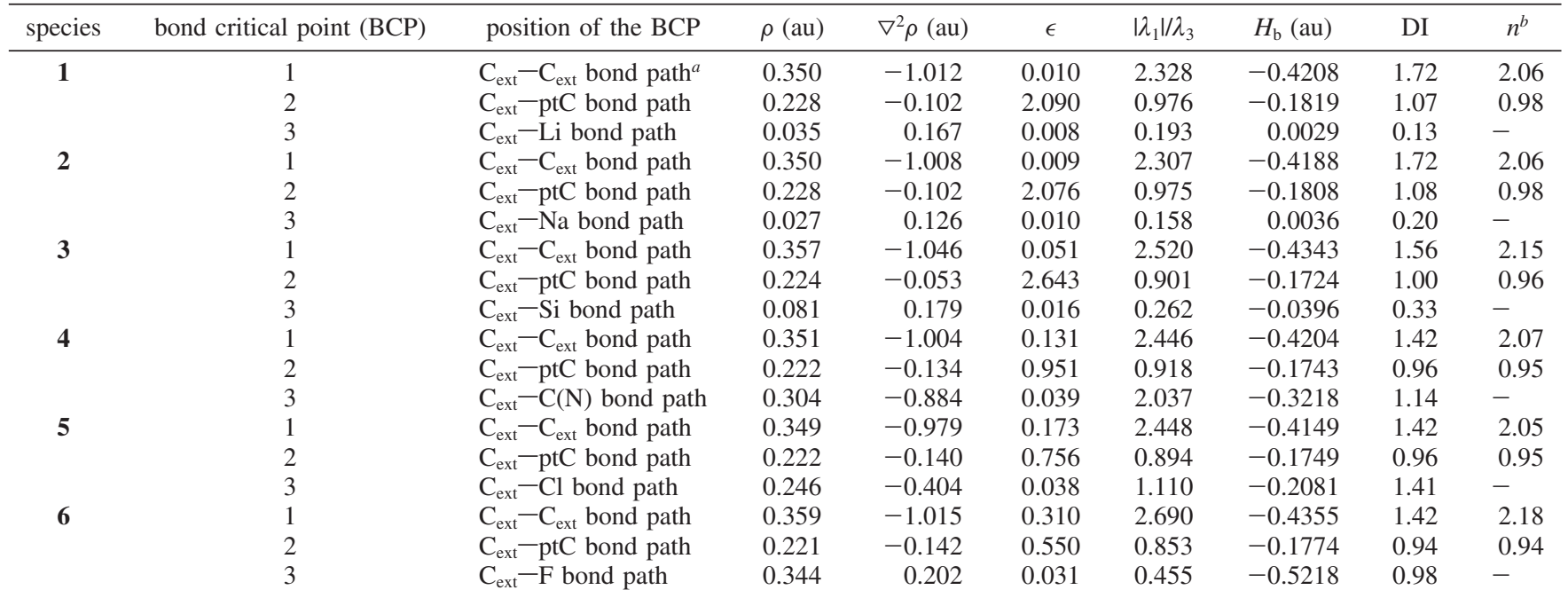

${ }^{a}$ These bonds involve vicinal atoms. ${ }^{b} n=\exp \left[A\left(\rho_{\mathrm{b}}-B\right)\right]$ is used only for $\mathrm{C}-\mathrm{C}$ bonds.

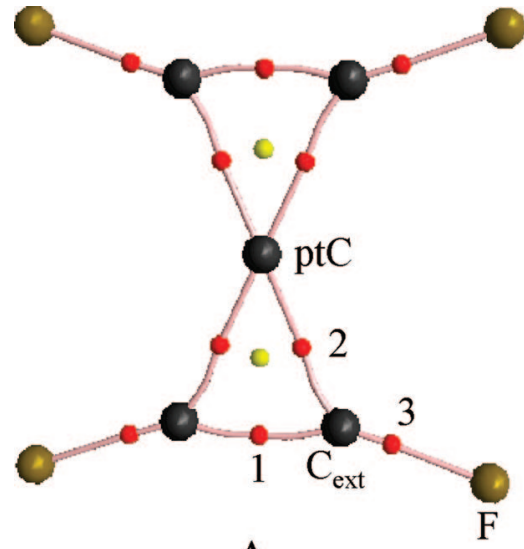

A

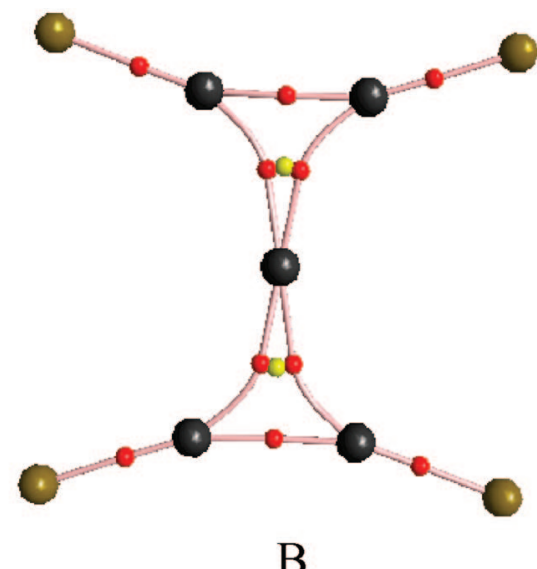

B

Figure 2. (A) Molecular graph of species 6 and (B) representation of its virial paths.

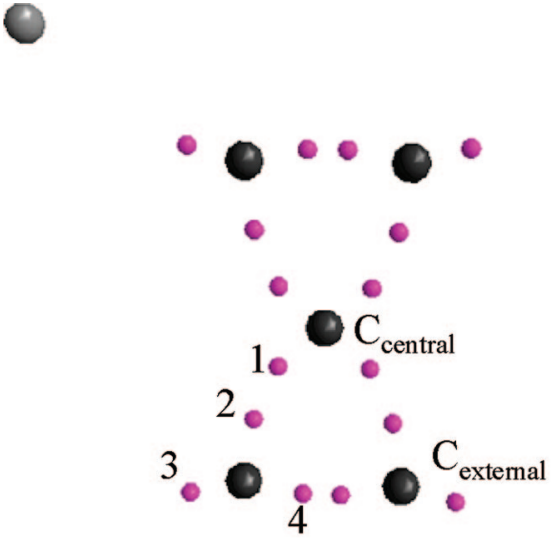

-

Figure 3. Valence-shell charge concentrations (VSCCs) of species $\mathbf{1}$.

the virial paths of the $\mathrm{C}_{5}$ skeleton are more toward the interior of the molecule than the corresponding bond paths. The same happens for all other species $(\mathbf{1}-\mathbf{5})$.

The charge densities $(\rho)$ of the BCPs between the external carbon atom and the ptC atom (BCP 2) in species $\mathbf{1}$ and $\mathbf{2}$ are slightly higher than those in species $\mathbf{3}-\mathbf{6}$, whereas the corresponding Laplacian of the charge density $\left(\nabla^{2} \rho\right)$ is more negative for species 4-6. The Laplacian $\left(\nabla^{2} \rho\right)$ of the charge density is the sum of the three eigenvalues of the Hessian matrix of the charge density $\left(\lambda_{1}, \lambda_{2}\right.$, and $\left.\lambda_{3}\right){ }^{31,46}$ A negative sign for $\nabla^{2} \rho$ represents the concentration of the charge density, and a positive sign for $\nabla^{2} \rho$ represents charge depletion. Thus, the charge density in BCP 2 is more concentrated in species $\mathbf{4 - 6}$. The charge density of BCP 2 in $\mathbf{3}$ is the least concentrated because its $\nabla^{2} \rho$ value is rather small.

The ellipticity $(\epsilon)$ is given by $\left(\lambda_{1} / \lambda_{2}\right)-1$, where $\lambda_{1}$ and $\lambda_{2}$ are eigenvalues of the Hessian matrix of the charge density. They represent the magnitudes of the eigenvectors $\vec{u}_{1}$ and $\vec{u}_{2}$, respectively. The eigenvectors $\vec{u}_{1}$ and $\vec{u}_{2}$ lie in a plane perpendicular to the bond path at the BCP between two bonding atoms. ${ }^{31}$ Then, the distribution of electron density is higher along the $\vec{u}_{1}$ direction at BCP 2 for species $\mathbf{1}-\mathbf{3}$. The distributions of the electron density at BCP 2 for species 4-6 are less asymmetrical (Table 3).

The ellipticity values at BCP 1 for species $\mathbf{1 - 3}$ are very close to zero. This indicates that the distribution of electron density at BCP 1 is very symmetrical for these species. The bond symmetry vanishes for species 4-6 at BCP 1, where the electron-withdrawing groups are bonded to the spiropentadiene 
skeleton. On the other hand, the values of the charge density and the corresponding Laplacians of the charge density at BCP 1 for all of the species are very similar (Table 3). Thus, although the $\mathrm{C}_{\mathrm{ext}}-\mathrm{C}_{\mathrm{ext}}$ bond of species $\mathbf{1}-\mathbf{6}$ have bond orders of nearly 2 , their corresponding ellipticities indicate that all of the bonds are not typical double bonds ( $\epsilon=0.350$ for ethylene), except for species 6. As for the ellipticities at BCP 2, species 1-3 and 4-6 have very different values. Once again, despite the fact that the corresponding bond orders indicate single bonds $(n=$ $1)$, the ellipticities do not fit the value of a typical single bond $(\epsilon=0)$.

The ratio $\left|\lambda_{1}\right| / \lambda_{3}$, in conjunction with other parameters, is used to classify chemical bonds. The ratio $\left|\lambda_{1}\right| / \lambda_{3}$ is greater than 1 for shared interactions (covalent-bond-like character) and much smaller than 1 for closed-shell interactions (ionic-bond-like character). ${ }^{31}$ The values of $\left|\lambda_{1}\right| / \lambda_{3}$ for $C_{\text {ext }}-C_{\text {ext }}$ in species 1 and 2 (nearly 2.3) are the smallest among the studied series. In contrast, the $\left|\lambda_{1}\right| / \lambda_{3}$ values for the $\mathrm{C}_{\text {ext }}-\mathrm{C}_{\text {central }}$ bond in $\mathbf{1}$ and $\mathbf{2}$ are the highest of the studied species, indicating that the strongly electron-donating alkaline atoms provide a better contribution to the interaction between the external $\mathrm{C}$ atoms and the ptC atom in the substituted spiropentadiene moiety (Table 3). Likewise, the total energy density $\left(H_{\mathrm{b}}\right)$ at BCP 2 in species 1 and $\mathbf{2}$ is smaller than those for the other species (3-6). This parameter reinforces the observation that the $\mathrm{C}_{\mathrm{ext}}-\mathrm{C}_{\text {central }}$ bonds are stronger for $\mathbf{1}$ and $\mathbf{2}$. In addition, the analysis of DI and bond order $(n)$ between the ptC atom and the external carbon atoms for species $\mathbf{1}$ and $\mathbf{2}$ shows that the charge-donating effect of the alkaline metals strengthens the $\mathrm{C}_{\text {ext }}-\mathrm{C}_{\text {central }}$ bonds (Table 3). Moreover, all of these topological parameters for the $\mathrm{C}_{\mathrm{ext}}-\mathrm{ptC}$ bonds in $\mathbf{1}$ and $\mathbf{2}$ parallel their status of having the highest energy barriers for tetrasubstituted spiropentadiene ring opening.

The chemical the bonds of $\mathrm{C}_{\mathrm{ext}}-\mathrm{Li}, \mathrm{C}_{\mathrm{ext}}-\mathrm{Na}$, and $\mathrm{C}_{\mathrm{ext}}-\mathrm{Si}$ atomic pairs are classified as closed-shell interactions because, at BCP 3, they have (1) a low value of the charge density, (2) positive signs of the Laplacian of the charge density, (3) positive signs of the total energy density, and (4) a $\left|\lambda_{1}\right| / \lambda_{3}$ ratio close to zero. In species $\mathbf{4}$, the DI between each external carbon atom of the $\mathrm{C}_{5}$ skeleton and the carbon atom of the cyano group is higher than that from a single bond, where single $\mathrm{C}-\mathrm{C}$ bonds have DI values between 0.99 and 0.95 .

Figure 3 shows all of the valence-shell charge concentrations (VSCCs) of species 1, which were obtained from the topological analysis of the Laplacian of the charge density. ${ }^{46,47}$ The VSCC graphs of the $\mathrm{C}_{5}$ skeleton are similar for all species 1-6. Each VSCC corresponds to the $(3,-3)$ critical point of the Laplacian of the charge density. A local maximum of the distribution of the charge density is represented by the $(3,-3)$ critical point of the Laplacian of the charge density.

Table 4 reports the values of the Laplacian of the charge density of the $(3,-3)$ critical points from the atomic graphs of species 1-6. An atomic graph represents a topological analysis of the critical points of the Laplacian of the charge density. The critical points of the Laplacian of the charge density are obtained where $\nabla\left(\nabla^{2} \rho\right)=0 .{ }^{31,43,48}$ From Table 4 , one can see that species $\mathbf{1}-\mathbf{3}$ have more concentration of the charge density near the $\mathrm{ptC}$ atom (at point 1). Conversely, for species 4-6, the two transition states have more concentration of the charge density near the external carbon atom of the $\mathrm{C}_{5}$ skeleton (at point 2). Nonetheless, there is a higher concentration of the charge density near the $\mathrm{ptC}$ atom than near the external carbon atoms of the $\mathrm{C}_{5}$ skeleton because of the higher magnitude of the Laplacian of the charge density at point 1 than at point 2
TABLE 4: Values of the Laplacian of the Charge Density $\left(\nabla^{2} \rho\right)$ of the $(3,-3)$ Critical Points from the Atomic Graphs of Species 1-6

\begin{tabular}{ccccc}
\hline & \multicolumn{3}{c}{$(3,-3)$ critical point from the Laplacian } & molecular graph $^{a}$ \\
\cline { 2 - 5 } species & 1 & 2 & 3 & 4 \\
\hline $\mathbf{1}$ & -0.672 & -0.352 & -1.040 & -1.182 \\
$\mathbf{2}$ & -0.668 & -0.359 & -0.987 & -1.180 \\
$\mathbf{3}$ & -0.682 & -0.381 & -1.089 & -1.192 \\
$\mathbf{4}$ & -0.657 & -0.387 & -1.132 & -1.152 \\
$\mathbf{5}$ & -0.638 & -0.394 & -0.820 & -1.136 \\
$\mathbf{6}$ & -0.660 & -0.405 & -0.680 & -1.172
\end{tabular}

${ }^{a}$ Points $1-4$ of the $(3,-3)$ critical points correspond to the points shown in Figure 3.

(Table 4). Likewise, the concentration of charge density between each bonding external carbon atom (at point 4) is higher in species $\mathbf{1}-\mathbf{3}$ than in species $\mathbf{4}-\mathbf{6}$.

The QTAIM analysis shows that there are no significant topological differences among the atomic basins of the ptC atoms of species 1-6, except for their electronic energy densities. However, the distributions of electron density in the valence region of the $\mathrm{C}_{5}$ skeleton for species $\mathbf{1}$ and $\mathbf{2}$ are very different from those of other species. The analysis of the results indicates that the electron-withdrawing groups remove charge density from $\mathrm{C}_{\mathrm{ext}}-\mathrm{C}_{\text {central }}$ bonds, which decreases the bond strength and, consequently, destabilizes the $\mathrm{C}_{5}$ skeleton. On the other hand, the electron-donating groups increase the charge density between $\mathrm{C}_{\text {ext }}$ and $\mathrm{C}_{\text {central }}$, and the tetrasubstituted piropentadiene moiety becomes more stable than the nonsubstituted analogue.

\section{Conclusions}

Electron-donating groups by resonance failed to afford stable derivatives of spiropentadiene dication with $\mathrm{ptC}$ atoms because resonance demands the participation of the $\pi$-electron system and the spiropentadiene moiety is mainly stabilized by $\sigma$ electrons. Otherwise, $\mathrm{Li}$ and $\mathrm{Na}$, which are good $\sigma$-bond donating groups, can stabilize the spiropentadiene system by increasing the charge density of $\mathrm{C}_{\mathrm{ext}}-\mathrm{C}_{\text {central }}$ bonds in relation to that in the nonsubstituted $\mathrm{C}_{5}$ dication. On the other hand, the electron-withdrawing groups remove the charge density from $\mathrm{C}_{\mathrm{ext}}-\mathrm{C}_{\text {central }}$ bonds, which decreases the bond strength and, consequently, destabilizes the $\mathrm{C}_{5}$ skeleton.

The stability of the spiropentadiene dication derivative toward the ring-opening reaction is related not only to the electronic energy density of $\mathrm{C}_{5}$ skeleton, but also to the distribution of electron density in the valence region of the $\mathrm{C}_{5}$ skeleton.

The distributions of electron density in the valence region of the $\mathrm{C}_{5}$ skeletons of species $\mathbf{1}$ and $\mathbf{2}$ are very different from those of other species. In species $\mathbf{1 - 3}$, the distributions of charge density along the $\vec{u}_{1}$ direction between the ptC atom and the external carbon atom of the $\mathrm{C}_{5}$ skeleton are highly asymmetrical. Species $\mathbf{1}$ and $\mathbf{2}$ have the highest values of DI between the ptC atom and the external carbon atoms and the smallest energy density along the corresponding bond paths. Likewise, the DIs between the vicinal external carbon atoms of the $C_{5}$ skeleton are higher in species $\mathbf{1}$ and $\mathbf{2}$. The corresponding distributions of electron density in the $\mathrm{C}_{\mathrm{ext}}-\mathrm{C}_{\text {ext }}$ bond are very symmetrical for species $\mathbf{1}$ and $\mathbf{2}$. In addition, species $\mathbf{1 - 3}$ have higher concentrations of charge density near the $\mathrm{ptC}$ atom and between each pair of external carbon atoms, whereas for $\mathbf{4 - 6}$, the charge density is more concentrated on the external carbon atoms.

Acknowledgment. The authors thank FAPERJ and $\mathrm{CNPq}$ for financial support. 


\section{References and Notes}

(1) Keese, R. Chem. Rev. 2006, 106, 4787-4808. 972 .

(2) Boldyrev, A. I.; Simons, J. J. Am. Chem. Soc. 1998, 120, 7967-

(3) Choukroun, R.; Donnadieu, B.; Zhao, J. S.; Cassoux, P.; Lepetit,

C.; Silvi, B. Organometallics 2000, 19, 1901-1911.

(4) Collins, J. B.; Dill, J. D.; Jemmis, E. D.; Apeloig, Y.; Schleyer,

P. V.; Seeger, R.; Pople, J. A. J. Am. Chem. Soc. 1976, 98, 5419-5427.

(5) Erker, G.; Albrecht, M.; Kruger, C.; Werner, S. Organometallics 1991, 10, 3791-3793.

(6) Hoffmann, R.; Alder, R. W.; Wilcox, C. F. J. Am. Chem. Soc. 1970, 92, 4992-\&.

(7) Minyaev, R. M.; Gribanova, T. N.; Minkin, V. I.; Starikov, A. G.; Hoffmann, R. J. Org. Chem. 2005, 70, 6693-6704.

(8) Rottger, D.; Erker, G.; Frohlich, R.; Grehl, M.; Silverio, S. J.; Hylakryspin, I.; Gleiter, R. J. Am. Chem. Soc. 1995, 117, 10503-10512. (9) Sorger, K.; Schleyer, P. V. J. Mol. Struct. (THEOCHEM) 1995, $338,317-346$. 995.

(10) Wang, Z. X.; Schleyer, P. V. J. Am. Chem. Soc. 2001, 123, 994-

(11) Perez, N.; Heine, T.; Barthel, R.; Seifert, G.; Vela, A.; MendezRojas, M. A.; Merino, G. Org. Lett. 2005, 7, 1509-1512.

(12) McGrath, M. P.; Radom, L. J. Am. Chem. Soc. 1993, 115, 33203321.

(13) McGrath, M. P.; Radom, L.; Schaefer, H. F. J. Org. Chem. 1992, 57, 4847-4850.

(14) Wong, M. W.; Radom, L. J. Am. Chem. Soc. 1989, 111, 11551156.

(15) Rasmussen, D. R.; Radom, L. Angew. Chem., Int. Ed. 1999, 38, 2876-2878.

(16) Rottger, D.; Erker, G. Angew. Chem., Int. Ed. Engl. 1997, 36, 813827.

(17) Wang, Z. X.; Zhang, C. G.; Chen, Z. F.; von Ragu Schleyer, P. Inorg. Chem. 2008, 47, 1332-1336.

(18) Firme, C. L.; Barreiro, N. B. P.; Esteves, P. M.; Correa, R. J. J. Phys. Chem. A 2008, 112, 686-692.

(19) Wu, Y. B.; Yuan, C. X.; Gao, F.; Lu, H. G.; Guo, J. C.; Li, S. D.; Wang, Y. K.; Yang, P. Organometallics 2007, 26, 4395-4401.

(20) Xie, H. B.; Ding, Y. H. J. Chem. Phys. 2007, 126.

(21) Yang, L. M.; Ding, Y. H.; Sun, C. C. J. Am. Chem. Soc. 2007, $129,658-665$.

(22) Sateesh, B.; Reddy, A. S.; Sastry, G. N. J. Comput. Chem. 2007, $28,335-343$.

(23) Lammertsma, K.; Schleyer, P. V. J. Phys. Chem. 1988, 92, 881886 .

(24) Priyakumar, U. D.; Reddy, A. S.; Sastry, G. N. Tetrahedron Lett. 2004, 45, 2495-2498.

(25) Priyakumar, U. D.; Sastry, G. N. Tetrahedron Lett. 2004, 45, 15151517.

(26) Merino, G.; Mendez-Rojas, M. A.; Beltraan, H. I.; Corminboeuf, C.; Heine, T.; Vela, A. J. Am. Chem. Soc. 2004, 126, 16160-16169.

(27) Merino, G.; Mendez-Rojas, M. A.; Vela, A. J. Am. Chem. Soc. 2003, $125,6026-6027$.
(28) Pancharatna, P. D.; Mendez-Rojas, M. A.; Merino, G.; Vela, A.; Hoffmann, R. J. Am. Chem. Soc. 2004, 126, 15309-15315.

(29) Merino, G.; Mendez-Rojas, M. A.; Vela, A.; Heine, T. J. Comput. Chem. 2007, 28, 362-372.

(30) Esteves, P. M.; Ferreira, N. B. P.; Corrêa, R. J. J. Am. Chem. Soc. 2005, 127, 8680-8685.

(31) Bader, R. F. W. Atoms in Molecules: A Quantum Theory, 1st ed.; Oxford University Press: Oxford, U.K., 1994.

(32) Matta, C. F.; Boyd, R. J. In The Quantum Theory of Atoms in Molecules-From Solid to DNA and Drug Design, Matta, C. F., Boyd, R. J., Eds.; Wiley-VCH: Weinheim, Germany, 2007; pp 1-34.

(33) Popelier, P. L. A. Atoms in Molecules: An Introduction, 1st ed.; Prentice Hall: Manchester, U.K., 2000.

(34) Fletcher, R. Practical Methods of Optimization; Wiley: New York, 1980; Vol. 1

(35) Becke, A. D. J. Chem. Phys. 1993, 98, 5648-5652.

(36) Becke, A. D. J. Chem. Phys. 1993, 98, 1372-1377.

(37) Dunning, J. T. H. J. Chem. Phys. 1989, 90, 1007-1023.

(38) Lee, C.; Yang, W.; Parr, R. G. Phys. Rev. B 1988, 37, 785.

(39) Ernzerhof, M.; Scuseria, G. E. J. Chem. Phys. 1999, 110, 50295036 .

(40) Frisch, M. J.; Trucks, G. W.; Schlegel, H. B.; Scuseria, G. E.; Robb, M. A.; Cheeseman, J. R.; Zakrzewski, V. G.; Montgomery, J. A., Jr.; Vreven, T.; Kudin, K. N.; Burant, J. C.; Millam, J. M.; Iyengar, S. S.; Tomasi, J.; Barone, V.; Mennucci, B.; Cossi, M.; Scalmani, G.; Rega, N.; Petersson, G. A.; Nakatsuji, H.; Hada, M.; Ehara, M.; Toyota, K.; Fukuda, R.; Hasegawa, J.; Ishida, M.; Nakajima, T.; Honda, Y.; Kitao, O.; Nakai, H.; Klene, M.; Li, X.; Knox, J. E.; Hratchian, H. P.; Cross, J. B.; Adamo, C.; Jaramillo, J.; Gomperts, R.; Stratmann, R. E; Yazyev, O.; Austin, A. J.; Cammi, R.; Pomelli, C.; Ochterski, J. W.; Ayala, P. Y.; Morokuma, K.; Voth, G. A.; Salvador, P.; Dannenberg, J. J.; Zakrzewski, V. G.; Dapprich, S.; Daniels, A. D.; Strain, M. C.; Farkas, O.; Malick, D. K.; Rabuck, A. D.; Raghavachari, K.; Foresman, J. B.; Ortiz, J. V.; Cui, Q.; Baboul, A. G.; Clifford, S.; Cioslowski, J.; Stefanov, B. B.; Liu, G.; Liashenko, A.; Piskorz, P.; Komaromi, I.; Martin, R. L.; Fox, D. J.; Keith, T.; Al-Laham, M. A.; Peng, C. Y.; Nanayakkara, A.; Challacombe, M.; Gill, P. M. W.; Johnson, B.; Chen, W.; Wong, M. W.; Gonzalez, C.; Pople, J. A. Gaussian 03, revision B.04; Gaussian, Inc.: Pittsburgh, PA, 2003.

(41) Biegler-König, F.; Schönbohm, J. AIM2000, version 2.0; 2002.

(42) Bader, R. F. W.; Stephens, M. E. J. Am. Chem. Soc. 1975, 97, $7391-7399$.

(43) Bader, R. F. W.; Streitwieser, A.; Neuhaus, A.; Laidig, K. E.; Speers, P. J. Am. Chem. Soc. 1996, 118, 4959-4965.

(44) Firme, C. L.; Antunes, O. A. C.; Esteves, P. M. Chem. Phys. Lett. 2009, 468, 129-133.

(45) Bader, R. F. W. J. Phys. Chem. A 1998, 102, 7314-7323.

(46) Popelier, P. L. A. Coord. Chem. Rev. 2000, 197, 169-189.

(47) Popelier, P. L. A.; Burke, J.; Malcolm, N. O. J. Int. J. Quantum Chem. 2003, 92, 326-336.

(48) Malcolm, N. O. J.; Popelier, P. L. A. J. Phys. Chem. A 2001, 105, $7638-7645$.

JP807400J 